\title{
The binding characteristics of a cyclic nonapeptide, c(CGRRAGGSC), in LNCaP human prostate cancer cells
}

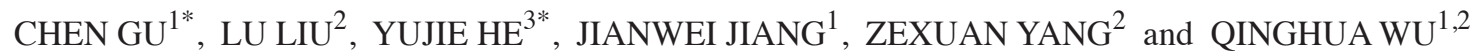 \\ ${ }^{1}$ Department of Radiology, The Third Affiliated Hospital of Nantong University, Wuxi 214042; \\ ${ }^{2}$ Nuclear Medicine Technology Institute, School of Medicine, Southeast University, Dingjiaqiao, \\ Nanjing 210009; ${ }^{3}$ Department of Radiology, The Fourth Hospital of Wuxi, Wuxi 214062, P.R. China
}

Received February 15, 2012; Accepted May 29, 2012

DOI: $10.3892 / \mathrm{ol} .2012 .769$

\begin{abstract}
Previous studies have demonstrated that interleukin-11 (IL-11) and the IL-11 receptor (IL-11R) are associated with the regulation of tumor progression and may play a significant role in bone metastases. The nonapeptide structure c(CGRRAGGSC) is a phage display-selected IL-11 mimic, which binds to IL-11R. The aim of this study is to investigate the binding characteristics of a cyclic nonapeptide $\mathrm{c}(\mathrm{CGRRAGGSC)}$ in LNCaP human prostate cancer cells. To investigate its binding and uptake effects, c(CGRRAGGSC) was labeled with a fluorescent dye, LSS670. The binding location of LSS670 cyclic nonapeptide in LNCaP cells was investigated by fluorescence microscopy. Flow cytometry was used to detect the fluorescence of LSS670-c(CGRRAGGSC) in LNCaP cells. The binding of LSS670-c(CGRRAGGSC) in LNCaP cells was inhibited by unlabeled cyclic nonapeptide, depending on the varying density of $\mathrm{c}(\mathrm{CGRRAGGSC})$ and different time points. The molecular probe bound to the LNCaP cell membrane and cytoplasm through fluorescence tracing. In the saturation experiments performed in vitro, the $\mathrm{K}_{\mathrm{d}}$ value was $3.2 \pm 0.02 \mathrm{nM}$ and the $\mathrm{B}_{\max }$ value was $754 \pm 34 \mathrm{fmol} / \mathrm{mg}$.pro. The $50 \%$ inhibiting concentration $\left(\mathrm{IC}_{50}\right)$ was $6.31 \pm 0.12 \mathrm{nmol} / 1$ and the $\mathrm{K}_{\mathrm{i}}$ value was $2.11 \pm 0.14 \mathrm{nmol} / \mathrm{l}$ in competitive inhibition experiments. Our results suggest that $\mathrm{c}$ (CGRRAGGSC) is able to specifically bind to LNCaP cells through a receptor-mediated pathway.
\end{abstract}

\section{Introduction}

Interleukin-11 (IL-11) is a cytokine that plays significant roles in various biological processes. It specifically interacts with

Correspondence to: Professor Qinghua $\mathrm{Wu}$, Department of Radiology, The Third Affiliated Hospital, Nantong University, No. 585 Xingyuanbei Road, Wuxi 214042, P.R. China

E-mail: qinghua_wu@yahoo.cn

*Contributed equally

Key words: LNCaP cells, interleukin-11 analog, fluorescent dyes, prostate cancer its receptor, the IL-11 receptor $\alpha$-chain (IL-11R), with a high affinity $(1,2)$. As a glycoprotein on the cell membrane, IL-11R, together with gp130 (the corresponding transmembrane signal transduction glycoprotein), forms a complex closely associated with the incidence and development of tumors (3-5). IL-11R is expressed at a high level and functions in the osseous metastasis process of various types of cancer, including prostate cancers (6-8). The IL-11 analog c(Cys-Gly-Arg-Arg-Ala -Gly-Gly-Ser-Cys) $\mathrm{NH}_{2}$, written as c(CGRRAGGSC), is an artificially synthesized nonapeptide which has been demonstrated to contain a locus that specifically binds to the IL-11R $\alpha$-chain by using phage display technology (9). The present study evaluates the possibility of using c(CGRRAGGSC) as the exogenous ligand of LNCaP cells and provides experimental evidence for the visualization of tissues and organs of experimental animals. This research uses a near-infrared dye LSS670 and technetium 99m as probes to investigate the binding characteristics of c(CGRRAGGSC) in human prostate cancer LNCaP cells in vitro. Our results provide a basis for the research of the specific molecular targeting used for the diagnosis of prostate cancer bone metastasis and further treatment of prostate carcinoma in the future.

\section{Materials and methods}

Reagents and cell lines. c(CGRRAGGSC) was purchased from Shanghai Target Biological (Shanghai, China). LSS670 fluorescent dye (excitation, $670 \mathrm{~nm}$; emission, $755 \mathrm{~nm}$ ) was provided by Dr Si Xiaoning from the Molecular Imaging Department of Carestream Health (Shanghai, China). ${ }^{99 m} \mathrm{Tc}$ washing buffer was purchased from Nanjing Senke Technology (Nanjing, China). Human prostate cancer LNCaP cells were purchased from Nanjing Kaiji Biological (Nanjing, China). The $\gamma$ calculator was purchased from Hewlett-Packard (Palo Alto, CA, USA). The CP224S micro-dose weighing instrument was purchased from Sartorius (Goettingen, Germany). The FACS Calibur cell flow instrument was purchased from BD Biosciences (Franklin Lakes, NJ, USA). The LS-55 fluorescence spectroscopic indicator was purchased from Perkin-Elmer (Waltham, MA, USA).

Counterstaining of LSS670-c(CGRRAGGSC). LSS670 is a near-infrared dye with an excitation maximum of $670 \mathrm{~nm}$ and 
a long Stoke's shift (LSS) of $85 \mathrm{~nm}$. LSS670-c(CGRRAGGSC) was obtained as described below. LSS670 dye (1 mg) was dissolved in $100 \mu \mathrm{l}$ of DMSO, followed by agitation for $10 \mathrm{sec}$ and incubation at room temperature for $15 \mathrm{~min}$. Immediately, $15 \mu \mathrm{l}$ of the dye solution was added to $30 \mu \mathrm{l}$ of the $\mathrm{c}(\mathrm{CGR}$ RAGGSC) solution. The $\mathrm{pH}$ was adjusted to 7.6 with $0.1 \mathrm{M}$ PBS to obtain a reaction volume of $500 \mu \mathrm{l}$. The reaction solution was gently mixed for $1 \mathrm{~h}$. The solution was purified using a Bio-Gel P-30 gel column, with a $10 \mu \mathrm{l}$ injection volume and a $0.5 \mathrm{ml} / \mathrm{min}$ flow rate. The eluent was then collected using a tube. Following incubation of the LNCaP cells in $10 \mu \mathrm{l}$ of LSS670-c(CGRRAGGSC) $(200 \mathrm{nM})$ at $37^{\circ} \mathrm{C}$ for $4 \mathrm{~h}, 10 \mu \mathrm{l}$ of $1 \mu \mathrm{g} / \mathrm{ml}$ 4',6-diamidino-2-phenylindole (DAPI) dye was added. DAPI was removed following incubation at room temperature for 5-10 min. The cells were rinsed 2-3 times with PBS to remove free DAPI. The solution was agitated for $1 \mathrm{~h}$ and mounted onto a Fisherbrand cover glass. The distribution of LSS670-c(CGRRAGGSC) in LNCaP cells was then observed using a fluorescence microscope (Olympus-X36, Olympus Corporation, Tokyo, Japan). The same procedure was performed with normal prostate epithelium cells that were deficient in the IL-11 receptor and served as the controls.

Fluorescence labeling of LNCaP cells by c(CGRRAGGSC). LNCaP cells were placed into 6 -well plates $\left(1 \times 10^{6}\right.$ cells $\left./ \mathrm{ml}\right)$ and LSS670-c(CGRRAGGSC) was synthesized as described above. In the concentration/effect experiment, LNCaP cells were incubated at $4^{\circ} \mathrm{C}$ for $4 \mathrm{~h}$ and then $37^{\circ} \mathrm{C}$ for $4 \mathrm{~h}$ with $\mathrm{c}$ (CGRRAGGSC) of varying concentrations $(0,20,50,100$, 200, 500 and 1,000 $\mathrm{nM})$. In the time/effect experiment, $\mathrm{LNCaP}$ cells were incubated with $200 \mathrm{nM} \mathrm{c}(\mathrm{CGRRAGGSC})$ at $4^{\circ} \mathrm{C}$ for $4 \mathrm{~h}$, followed by incubation at $37^{\circ} \mathrm{C}$ for $0,0.125,0.25,0.5,1,2$, 4,6 or $8 \mathrm{~h}$. In the competition inhibition experiment, LNCaP cells were incubated with unlabeled c(CGRRAGGSC) of varying concentrations $(20,50,100,200,500$ and 1,000 nM) at $37^{\circ} \mathrm{C}$ for $4 \mathrm{~h}$. LSS670-c(CGRRAGGSC) (200 nM) was added to the reaction system for another $4-\mathrm{h}$ incubation at $37^{\circ} \mathrm{C}$. In the experiments described above, a nonapeptide c(CGSPGWVRC) served as the control. A fluorescence microscope was used to observe the distribution of LSS670c(CGRRAGGSC) in LNCaP cells.

Radiolabeling. DTPA-c(CGRRAGGSC) was synthesized using the method described previously (10). The radiolabeling of DTPA-c(CGRRAGGSC) was performed as follows. Briefly, $20 \mu \mathrm{g}$ DTPA-c(CGRRAGGSC), $20 \mu \mathrm{l}$ of $1 \mathrm{mg} / \mathrm{ml} \mathrm{SnCl} \mathrm{S}_{2}$ and $280 \mu \mathrm{l}$ of $0.075 \mathrm{M}$ phosphate-buffered saline (PBS) were mixed and agitated at room temperature for $2 \mathrm{~min}$. This was followed by the addition of $0.2 \mathrm{ml}$ of ${ }^{99 \mathrm{~m}} \mathrm{Tc}$ eluent $(370-740 \mathrm{MBq}$ ). Following incubation at room temperature for $30 \mathrm{~min}$, the labeled product ${ }^{99 \mathrm{~m}}$ Tc-DTPA-c(CGRRAGGSC) was obtained. Analytical HPLC was performed using an SCL-10AVP HPLC system equipped with an EKA Chemicals reverse phase C-18 analytical column (KR100-5, 250x4.6 mm). The flow rate was $1 \mathrm{ml} / \mathrm{min}$. The samples were eluted with $\mathrm{H}_{2} \mathrm{O}$ /acetonitrile containing $0.15 \%$ trifluoroacetic acid of three linear gradients (A, 0-40\%; B, 10-80\%; and C, 30-100\%, each for $30 \mathrm{~min}$ ). The resultant eluent was collected in a tube. The fluorescence properties (ultraviolet wavelength, $210 \mathrm{~nm}$ ) were measured with a PDA100 ultraviolet detector (Shimadzu Co., Kyoto, Japan).
The stability of ${ }^{99 m}$ Tc-DTPA-c(CGRRAGGSC) in vitro was measured at different time points.

Saturation binding analysis in vitro. Aliquots $(75 \mu \mathrm{l})$ of the sample extracts were incubated for $30 \mathrm{~min}$ at $4^{\circ} \mathrm{C}$ with $50 \mu \mathrm{l}$ of $0.5 \%$ Tris buffer solution containing varying concentrations (0.1-10 nM) of ${ }^{99 \mathrm{~m}}$ Tc-DTPA-c(CGRRAGGSC). Parallel incubations were conducted in the presence of $1 \mu \mathrm{M}$ unlabeled DTPA-c(CGRRAGGSC) to determine the non-specific binding (NSB) at each ${ }^{99 \mathrm{~m}}$ Tc-DTPA-c(CGRRAGGSC) concentration. When the samples were mixed, the radioactivity of each tube in the sample group was measured and the mean dpm (disintegrations per min) of the tubes was used as total radioactivity. The samples were incubated at $25^{\circ} \mathrm{C}$ for $90 \mathrm{~min}$ with gentle agitation. The reactions were terminated by the addition of $1 \mathrm{ml}$ cold Tris buffer. The samples were centrifuged at $10,000 \mathrm{rpm}$ for $15 \mathrm{~min}$ at $4^{\circ} \mathrm{C}$ and the precipitates were washed with cold buffer. Following two more washes, specific binding (SB) was calculated as the difference between total binding [measured in the absence of DTPA-c(CGRRAGGSC)] and NSB [measured in the presence of DTPA-c(CGRRAGGSC)]. A saturation curve was created with $\mathrm{dpm}$ as the ordinate and the quantity of added ${ }^{99 \mathrm{~m}} \mathrm{Tc}-\mathrm{DTPA}-\mathrm{c}(\mathrm{CGR}$ AGGSC) as the abscissa. The equilibrium dissociation constant $\left(\mathrm{K}_{\mathrm{d}}\right)$ and the maximum binding capacity $\left(\mathrm{B}_{\max }\right)$ of the receptor were obtained by Scatchard analysis.

Competitive inhibition experiment in vitro. Aliquots (75 $\mu \mathrm{l}$ ) of the sample extracts were incubated for $30 \mathrm{~min}$ at $4^{\circ} \mathrm{C}$ with $50 \mu \mathrm{l}$ of $0.5 \%$ Tris buffer containing $1 \mathrm{nmol}$ of ${ }^{99 \mathrm{~m}} \mathrm{Tc}-\mathrm{DTPA}-\mathrm{c}(\mathrm{CGR}$ RGGSC). In addition, parallel experiments were conducted in the presence of unlabeledDTPA$\mathrm{c}(\mathrm{CGR}$ RAGGSC) of varying concentrations $(0.1-10 \mu \mathrm{M})$ to determine NSB. The procedures conducted were the same as those described in saturation binding analysis. A competitive inhibition curve was created with SB as the ordinate and the amount of added unlabeled DTPA-c(CGRRAGGSC) as the abscissa. The $50 \%$ inhibiting concentration $\left(\mathrm{IC}_{50}\right)$ and the equilibrium inhibition constant $\left(\mathrm{K}_{\mathrm{i}}\right)$ were calculated.

Statistical analyses. The measurements were expressed as means \pm standard deviation ( $\pm \mathrm{sd}$ ) and analyzed using one-way ANOVA. $\mathrm{P}<0.05$ was considered to indicate a statistically significant result. Each experiment was repeated at least three times.

\section{Results}

Binding characteristics of LSS670-c(CGRRAGGSC) in LNCAP cells. To investigate the binding characteristics of c(CGRRAGGSC) in LNCaP cells, c(CGRRAGGSC) was labeled with a fluorescent dye, LSS670, generating the probe LSS670-c(CGRRAGGSC). In the concentration/effect experiments, LNCaP cells were incubated with varying concentrations $(0,20,50,100,200,500$ and 1,000 $\mathrm{nM})$ of LSS670-c(CGRRAGGSC). This was followed by detection of the fluorescence intensity within cells with a fluorescence microscope. As shown in Fig. 1, the fluorescence intensity of the cells incubated with $200 \mathrm{nM}$ LSS670-c(CGRRAGGSC) was 6.58-fold higher than that of cells incubated with $20 \mathrm{nM}$ 


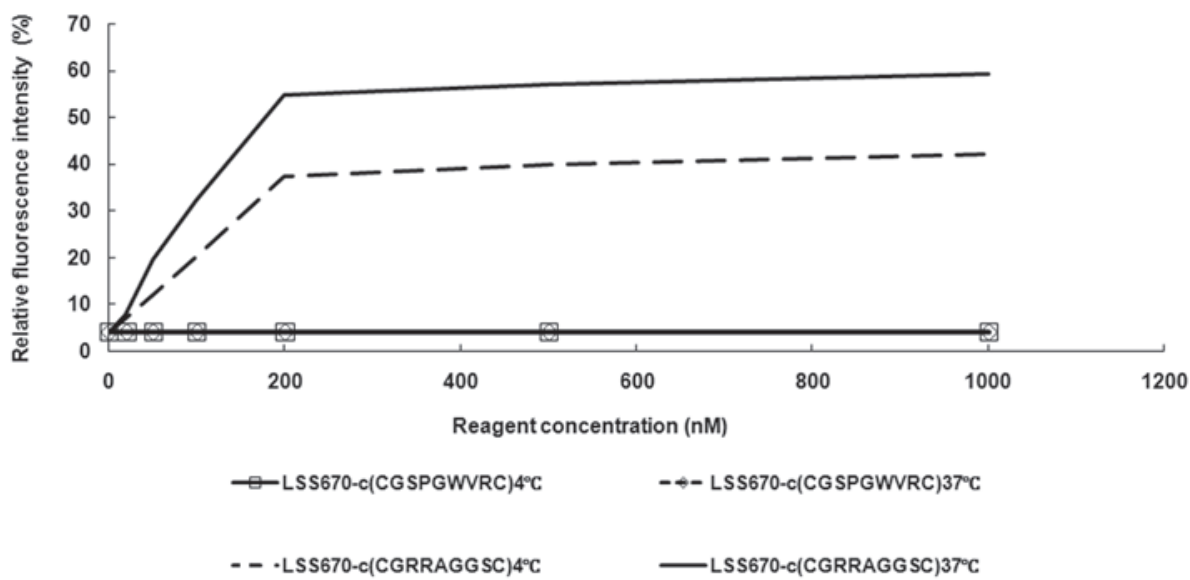

Figure 1. Concentration/effect experiments. LNCaP cells were incubated with varying concentrations $(0,20,50,100,200,500$ and $1,000 \mathrm{nM})$ of the LSS670-c(CGRRAGGSC) probes, followed by the detection of the fluorescence intensity within cells with a fluorescence microscope. A nonapeptide $\mathrm{c}(\mathrm{CGSPGWVRC})$ served as the control.

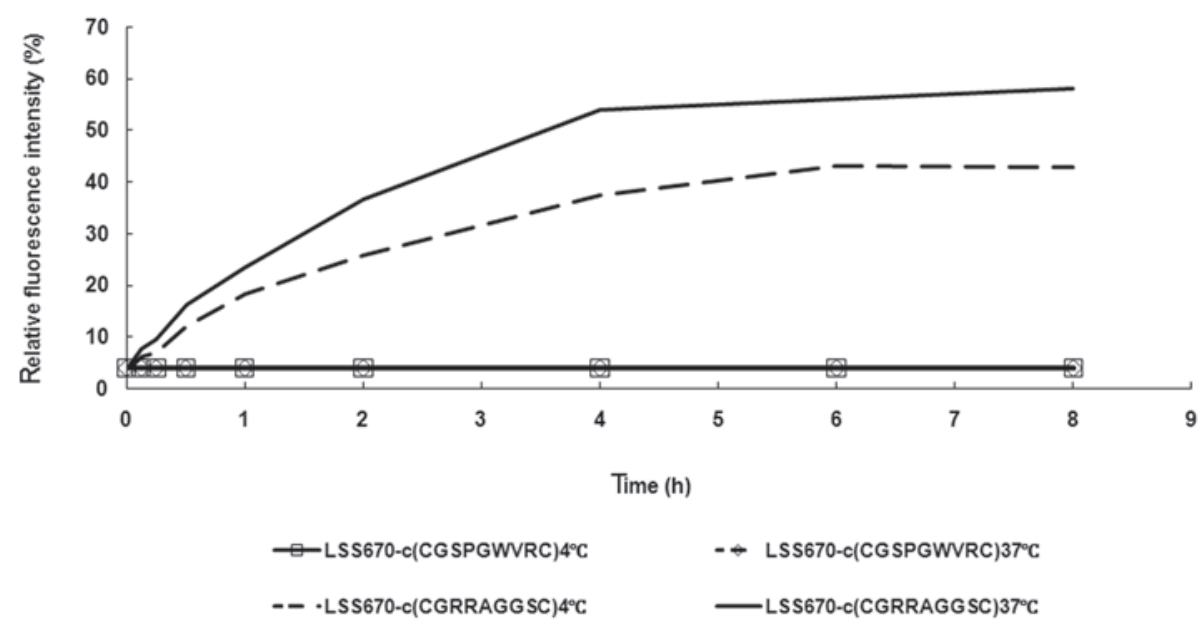

Figure 2. Time/effect experiment. LNCaP cells were incubated with $200 \mathrm{nM} \mathrm{LSS670-c(CGRRAGGSC)}$ at $4^{\circ} \mathrm{C}$ for $4 \mathrm{~h}$, followed by continued incubation at $37^{\circ} \mathrm{C}$ for varying time courses $(0,0.125,0.25,0.5,1,2,4,6$ or $8 \mathrm{~h}$. A nonapeptide c(CGSPGWVRC) served as the control.

LSS670-c(CGRRAGGSC), while the fluorescence intensity of the cells incubated with $500 \mathrm{nM}$ LSS670-c(CGRRAGGSC) was only 1.2-fold higher than cells incubated with $200 \mathrm{nM}$ LSS670-c(CGRRAGGSC). In cells incubated with a nonapeptide $\mathrm{c}(\mathrm{CGSPGWVRC})$, which served as a control probe, no fluorescence was detected.

In the time/effect experiment, $\mathrm{LNCaP}$ cells were incubated with $200 \mathrm{nM} \mathrm{LSS670-c(CGRRAGGSC)} \mathrm{at} 4^{\circ} \mathrm{C}$ for $4 \mathrm{~h}$, followed by continued incubation at $37^{\circ} \mathrm{C}$ for various time courses $(0,0.125,0.25,0.5,1,2,4,6$ or 8 h). As shown in Fig. 2, the fluorescence intensity within cells incubated with the control probe LSS670-c(CGSPGWVRC) was always extremely low at different incubation times (from 0 to $8 \mathrm{~h}$ ) at either $4^{\circ} \mathrm{C}$ or $37^{\circ} \mathrm{C}$. However, the fluorescence was detected in LNCaP cells incubated with LSS670-c(CGRRAGGSC) for $0.125 \mathrm{~h}$ or longer at $37^{\circ} \mathrm{C}$. The fluorescence intensity within cells incubated with LSS670-c(CGRRAGGSC) at $37^{\circ} \mathrm{C}$ increased to a relatively high level at $4 \mathrm{~h}$ and then the intensity continued to increase gradually to the highest level at $8 \mathrm{~h}$. When compared with the cells incubated with the control probe LSS670-c(CGSPGWVRC), the fluorescence intensity in cells incubated with LSS670-c(CGRRAGGSC) was 105.68 -fold higher at $4 \mathrm{~h}\left(37^{\circ} \mathrm{C}\right)$. It was noted that when incubated with LSS670-c(CGRRAGGSC) at $4^{\circ} \mathrm{C}$, the fluorescence intensity in $\mathrm{LNCaP}$ cells reached its peak following 6-h incubation.

In the competition/inhibition experiment, LNCaP cells were incubated with varying concentrations $(20,50,100$, 200,500 and $1,000 \mathrm{nM}$ ) of unlabeled c(CGRRAGGSC) at $37^{\circ} \mathrm{C}$ for $4 \mathrm{~h}$. LSS670-c(CGRRAGGSC) $(200 \mathrm{nM})$ was then added into the reaction system for an additional 4-h incubation at $37^{\circ} \mathrm{C}$. In the experiments described above, a nonapeptide $\mathrm{c}(\mathrm{CGSPGWVRC})$ served as the control.

Competition inhibition curve. As shown in Fig. 3, the competition inhibition curve, which was drawn using the logarithm value of the fluorescence intensity in LNCaP cells to the concentration of unlabeled c(CGRRAGGSC), indicated that the LSS670-c(CGRRAGGSC) fluorescence intensity decreases with the increase in unlabeled c(CGRRAGGSC) concentration 


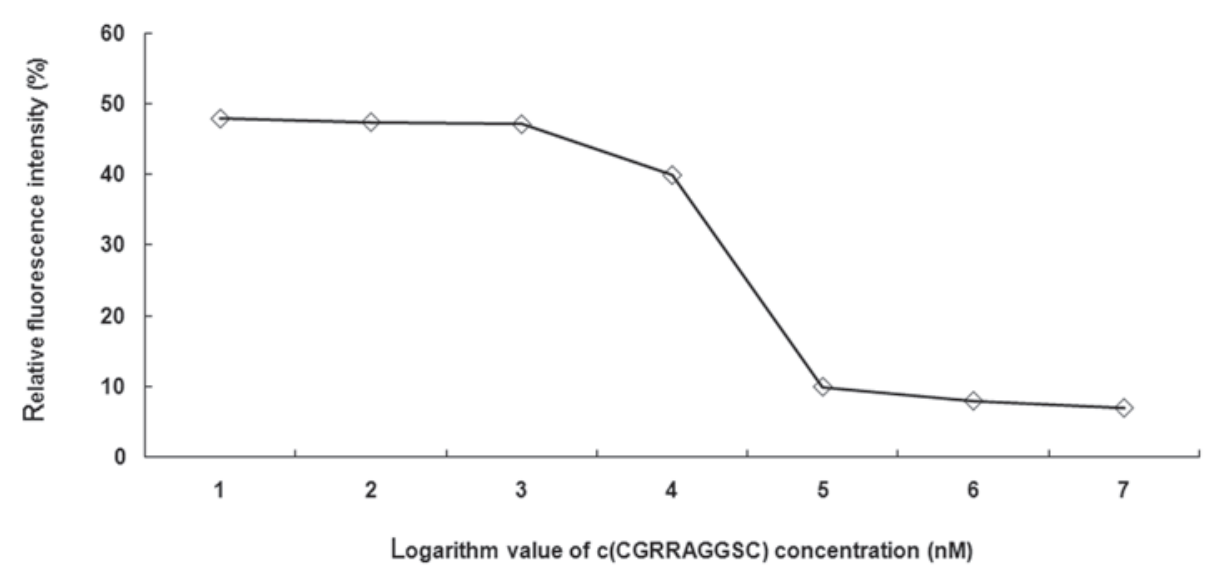

Figure 3. Competition/inhibition experiment. LNCaP cells were incubated with varying concentrations (20,50, 100, 200, 500 and 1,000 nM) of unlabeled $\mathrm{c}(\mathrm{CGRRAGGSC})$ at $37^{\circ} \mathrm{C}$ for $4 \mathrm{~h}$. Then, $200 \mathrm{nM} \mathrm{LSS670-c(CGRRAGGSC)}$ was added into the reaction system for another 4-h incubation at $37^{\circ} \mathrm{C}$.

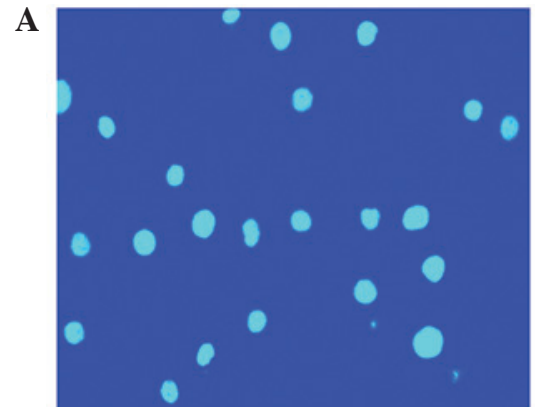

C

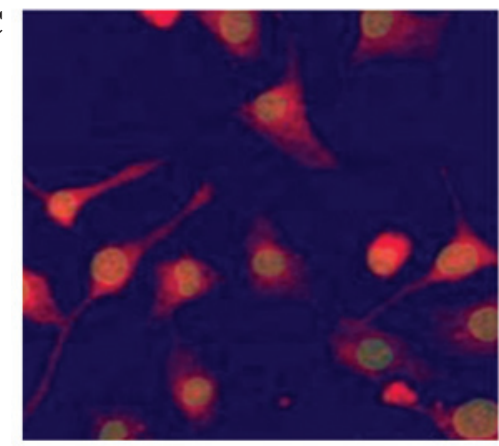

B

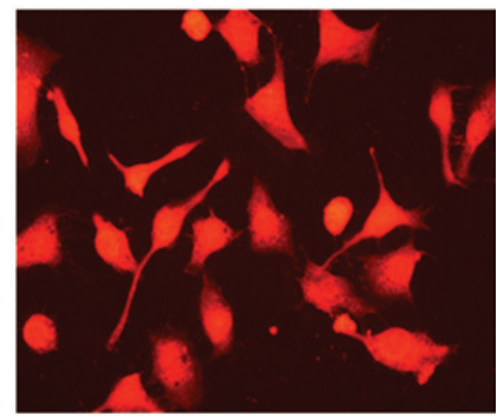

D

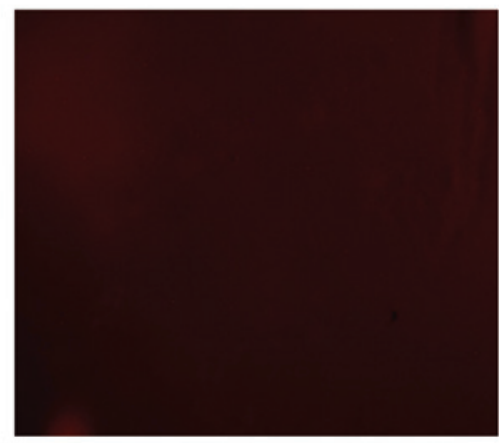

Figure 4. Cytochemical fluorescence of LSS670-c(CGRRAGGSC) in LNCaP cells (magnification, x200). (A) DAPI staining (excitation wavelength, $350 \mathrm{~nm}$; emission wavelength, $425 \mathrm{~nm}$ ) revealed blue staining of the nucleus (x200). (B) LSS670 labeling (excitation wavelength, $670 \mathrm{~nm}$; emission wavelength, $755 \mathrm{~nm}$ ) shows red staining of the cell membrane and cytoplasm (x200). (C) Merge fusion image (x100); (D) cells labeled with c(CGSPGWVRC) (x200). DAPI, 4',6-diamidino-2-phenylindole.

(Fig. 3). These results suggest that LNCaP cells are able to be specifically labeled by the LSS670-c(CGRRAGGSC) probes and that the probe binding efficacy is affected by the probe concentration and incubation time.

LSS670-c(CGRRAGGSC) localization. The majority of LSS670-c(CGRRAGGSC) was concentrated in the LNCaP cell membranes and cytoplasm. To investigate the localization of LSS670-c(CGRRAGGSC) probes in LNCaP cells, the LSS670-c(CGRRAGGSC)-labeled cells were stained with DAPI (excitation wavelength, $350 \mathrm{~nm}$; emission wavelength, $425 \mathrm{~nm}$ ) and observed through a fluorescence microscope. As shown in Fig. 4, the majority of LSS670-c(CGRRAGGSC) was concentrated in LNCaP cell membranes and cytoplasm
(Fig. 4A, B and C). No LSS670 fluorescence was demonstrated in the cell nucleus. No obvious LSS670 fluorescence was observed in the control cells labeled with LSS670c(CGSPGWVRC) (Fig. 4D). These results suggest that the binding between c(CGRRAGGSC) and LNCaP cells is specific.

Saturation binding analysis. The SB increased as the radioligand concentration increased, but gradually decreased as radioligand concentration approached saturation (Fig. 5A). NSB increased consistently as the radioligand concentration increased, without showing a tendency of saturation. The Scatchard plot is a straight line (Fig. 5B). Linear regression was used to determine the $K_{d}$ value and $B_{\max }$ value. The $K_{d}$ 
A

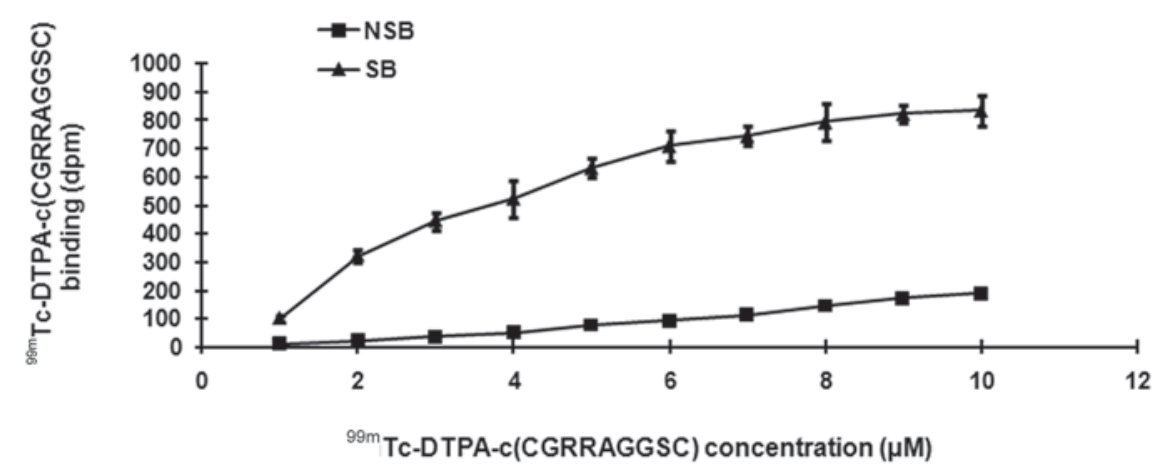

B

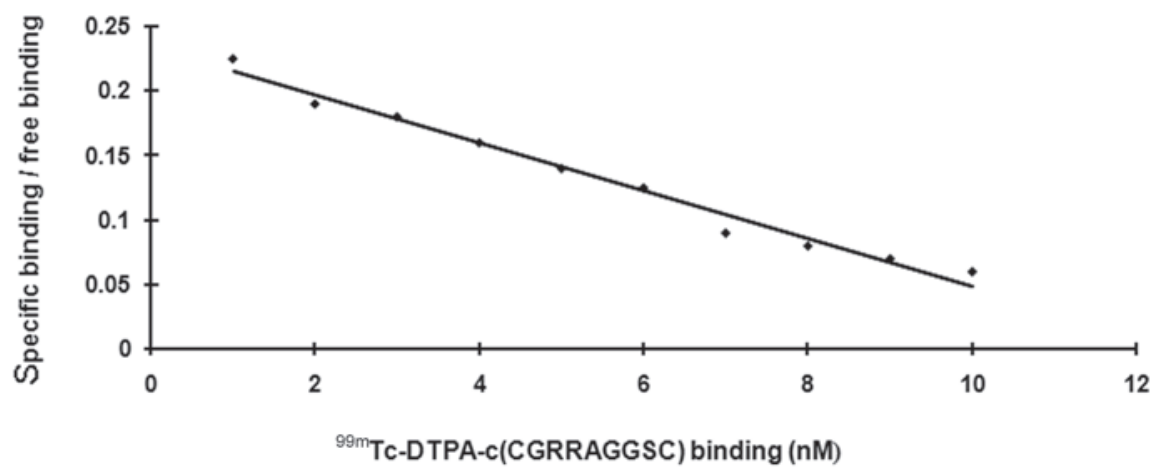

Figure 5. (A) Saturation binding data and (B) Scatchard analysis of ${ }^{99} \mathrm{~m}$ Tc-DTPA-c(CGRRAGGSC) binding in IL-11R of LNCaP cells. The samples were incubated for $90 \mathrm{~min}$ at $25^{\circ} \mathrm{C}$ with varying concentrations of ${ }^{99 \mathrm{~m}} \mathrm{Tc}-\mathrm{DTPA}-\mathrm{c}(\mathrm{CGRRAGGSC})$ in the presence or absence of $1 \mu \mathrm{M}$ unlabeled DTPA-c(CGRRAGGSC). Bars represent mean \pm standard error (SEM). IL-11, interleukin-11.

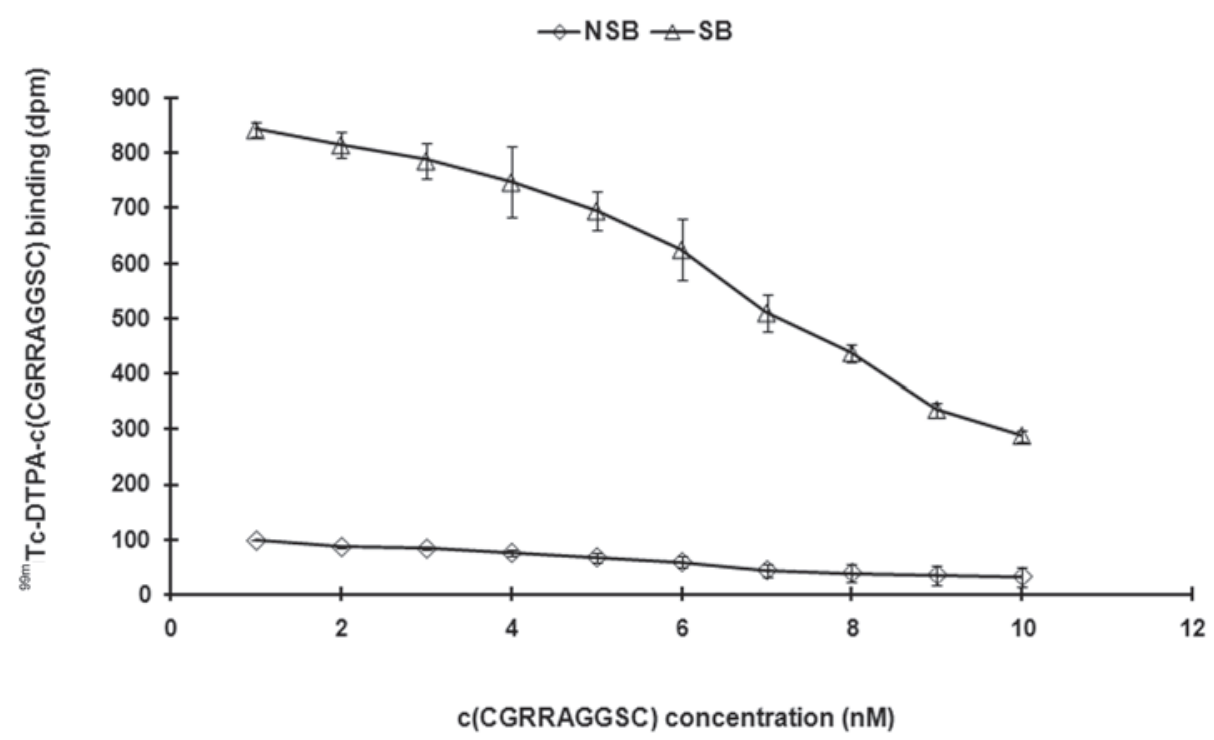

Figure 6 . Competitive binding data of ${ }^{99 \mathrm{~m} T c-D T P A-c(C G R R A G G S C)}$ binding in IL-11R of LNCaP cells. The samples were incubated for 90 min at $25^{\circ} \mathrm{C}$ with varying concentrations of unlabeled DTPA-c(CGRRAGGSC). Bars represent mean \pm standard error (SEM). IL-11, interleukin-11.

value was $3.2 \pm 0.02 \mathrm{nM}$. The $\mathrm{B}_{\max }$ value was $754 \pm 34 \mathrm{fmol} /$ mg.pro. These results suggest that the binding between $\mathrm{c}(\mathrm{CGRRAGGSC)}$ and LNCaP cells has sufficient affinity and provides further evidence for the existence of a receptor.

Competitive inhibition analysis. Unlabeled peptides were used to perform the competitive inhibition analysis. With
$\mathrm{c}(\mathrm{CGRR}$ AGGSC) concentrations in the reaction system gradually increasing $(0.1-10 \mu \mathrm{M})$, the binding of ${ }^{99 \mathrm{~m}} \mathrm{Tc}-\mathrm{DTPA}-$ $\mathrm{c}$ (CGRRAGGSC) to the receptor gradually decreased. The $\mathrm{IC}_{50}$ and the equilibrium inhibition constant $\left(\mathrm{K}_{\mathrm{i}}\right)$ were calculated $\left(\mathrm{IC}_{50}=6.31 \pm 0.12 \mathrm{nM}, \mathrm{K}_{\mathrm{i}}=2.11 \pm 0.14 \mathrm{nM}\right.$; Fig. 6). These results suggest that the labeled peptides and unlabeled peptides have the same biological activity. 


\section{Discussion}

The bone metastasis of human prostate cancer is a relatively long process, which can be difficult to diagnose. Early clinical diagnosis is particularly difficult since current medicines and biological agents lack targeted specificity to the cancer tissue due to their low deposition on the tumor and normal body structures. Due to the inaccuracy of drug effect, doses reaching the tumor are far from ideal $(11,12)$. A number of studies proved that IL-11, as a cytokine with multi-biological effects, when specifically bound with the $\alpha$-chain of its receptor, becomes a complex with high affinity for the intermembrane signal transduction glycoprotein 130 . The complex activates the Jak-STAT signal pathway and facilitates the phosphorylation of p-hydroxyphenylalanine kinase, thus exerting related biological effects $(6,13,14)$. Using phage display peptide library screening technology, it was revealed that the nonapeptide c(CGRRAGGSC), as an analog of IL-11, is able to specificically target to the prostate tumor. Previous studies have reported that when breast cancer cells undergo bone metastasis, they also generate IL-11, which accelerates the spread of tumor cells into the surrounding bones (15). Therefore, bone metastasis can be inhibited through the inhibition of the expression of IL-11. Kang et al revealed that the signaling pathway of IL-11 has a significant role in the bone metastasis of cancer, therefore bone metastasis may be specifically accelerated by raising the expression level of IL-11 (16). Other relevant studies have also demonstrated that IL-11 is closely associated with the occurrence and development of bone metastasis (17). Therefore, by employing an artificially synthesized nonapeptide as the ligand and determining its binding characteristics with human prostate cancer LNCaP cells, this study aimed to investigate the possibility of a nonapeptide as the specific external ligand of $\mathrm{LNCaP}$ cells in order to provide evidence for further studies.

Our team labeled c(CGRRAGGSC) with LSS670 and used fluorescence cytochemistry to investigate the binding characteristics of c(CGRRAGGSC) and human prostate cancer LNCaP cells. This method has the following advantages: i) LSS670-c(CGRRAGGSC) and LNCaP cells bind in a concentration-dependent manner and demonstrate a saturation tendency with increasing concentration. ii) LSS670-c(CGRRAGGSC) and LNCaP cells bind in a timedependent manner and demonstrate a saturation tendency with time. iii) The binding of LSS670-c(CGRRAGGSC) and $\mathrm{LNCaP}$ is challenged by the unlabeled nonapeptide $\mathrm{c}(\mathrm{CGRRAGGSC})$ and shows a clear competitive inhibition, which suggests that $\mathrm{c}$ (CGRRAGGSC) has the ability to bind with $\mathrm{LNCaP}$ cells but that the binding quantity is limited. Fluorescence microscopy revealed the concentration bound to the cell membranes. LSS670 labeling and ${ }^{99 \mathrm{~m}} \mathrm{Tc}$ did not affect the binding characteristics of c(CGRRAGGSC) and demonstrated a saturation tendency as well as competitive inhibition. In the binding experiments, internalization and releasing LSS670-c(CGRRAGGSC), it was revealed that c(CGRRAGGSC) acts with LNCaP cells via IL-11 and its receptor and may be released as its prototype, while the negative peptide in the control group has no such ability. It is that the specificity is resulted from binding of the receptor and the ligand; $\mathrm{K}_{\mathrm{d}}$ and $\mathrm{B}_{\max }$ are calculated as $3.2 \pm 0.02 \mathrm{nmol} / \mathrm{l}$ and
$754 \pm 34 \mathrm{fmol} / \mathrm{mg}$ pro, respectively, which proves that their binding has sufficient affinity and provides further evidence for the existence of the receptor. The nonapeptide has the ability to bind specifically with the surface receptor of $\mathrm{LNCaP}$ and become a complete membrane receptor, which meets the requirement of being an aglucone. This also suggests that c(CGRRAGGSC) and LSS670-c(CGRRAGGSC) compete in order to bind with sites on the cell membranes of LNCAP cells.

Near-infrared ray fluorescence imaging is a new optical visualization technology that observes structures and blood at greater depth due to its greater penetration ability and lower scattering activation disturbance (18-20). The present study used LSS670 to label c(CGRRAGGSC) as it has wider scope of activation and emission and quickly and specifically binds with the external amino groups of the nonapeptide as a new near-infrared ray fluorescent dye. This fluorescence labeling is observed using an appropriate light source, such as camera control (CC) and other optical detectors. This fluorescence labeling has better sensitivity and spatial resolution for realtime observation on sites in and outside of the cell membranes. The results of the study prove that the dye clearly visualizes the binding sites of c(CGRRAGGSC) and LNCaP cells and outperforms other near-infrared ray dyes including cy5.5. In further studies, the dye could be used to visualize the body structures of small animals.

Through the preliminary study of the binding characteristics of c(CGRRAGGSC) and LNCaP cells, we draw the conclusion that c(CGRRAGGSC) specifically binds to LNCaP cells through a receptor-mediated pathway.

\section{Acknowledgements}

We thank Dr Xiaoning Si for providing the LSS670 dye. This study was supported by the National Nature Scientific Research Foundation of China (30470500).

\section{References}

1. Du X and Williams DA: Interleukin-11: review of molecular, cell biology, and clinical use. Blood 89: 3897-3908, 1997.

2. Schleinkofer K, Dingley A, Tacken I, Federwisch M and Müller-Newen G: Identification of the domain in the human interleukin-11 receptor that mediates ligand binding. J Mol Biol 306: 263-274, 2001.

3. Dahmen H, Horsten U, Küster A, et al: Activation of the signal transducer gp130 by interleukin-11 and interleukin- 6 is mediated by similar molecular interactions. Biochem J 331: 695-702, 1998.

4. Kurth I, Horsten U, Pflanz S, et al: Activation of the signal transducer glycoprotein 130 by both IL- 6 and IL-11 requires two distinct binding epitopes. J Immunol 162: 1480-1487, 1999.

5. Zurita AJ, Troncoso P,Cardó-Vila M, Logothetis CJ, Pasqualini R and Arap W: Combinatorial screenings in patients: the interleukin-11 receptor alpha as a candidate target in the progression of human prostate cancer. Cancer Res 64: 435-439, 2004.

6. Nakayama T, Yoshizaki A, Izumida S, et al: Expression of interleukin-11(IL-11) and IL-11 receptor alpha in human gastric carcinoma and IL-11 upregulates the invasive activity of human gastric carcinoma cells. Int J Oncol 30: 825-833, 2007.

7. Yoshizaki A, Nakayama T, Yamazumi K, Yakata Y, Taba M and Sekine I: Expression of interleukin (IL)-11 and IL-11 receptor in human colorectal adenocarcinoma: IL-11 up-regulation of the invasive and proliferative activity of human colorectal carcinoma cells. Int J Oncol 29: 869-876, 2006.

8. Campbell CL, Jiang Z, Savarese DM and Savarese TM: Increased expression of the interleukin-11 receptor and evidence of STAT3 activation in prostate carcinoma. Am J Pathol 158: 25-32, 2001. 
9. Wang W, Ke S, Kwon S, et al: A new optical and nuclear dual-labeled imaging agent targeting interleukin 11 receptor alpha-chain. Bioconjug Chem 18: 397-402, 2007.

10. Cook RJ and Major P: Multistate analysis of skeletal events in patients with bone metastases. Clin Cancer Res 12: 6264s-6269s 2006.

11. Morgentaler A: Testosterone and prostate cancer: an historical perspective on a modern myth. Eur Urol 50: 935-939, 2006.

12. Ernst M, Najdovska M, Grail D, et al: STAT3 and STAT1 mediate IL-11-dependent and inflammation-associated gastric tumorigenesis in gp130 receptor mutant mice. J Clin Invest 118: 1727-1738, 2008

13. Nandurkar HH, Hilton DJ, Nathan P, Willson T, Nicola N and Begley CG: The human IL-11 receptor requires gp130 for signalling: demonstration by molecular cloning of the receptor. Oncogene 12: 585-593, 1996.

14. Morgan H, Tumber A and Hill PA: Breast cancer cells induce osteoclast formation by stimulating host IL-11 production and downregulating granulocyte/macrophage colony-stimulating factor. Int J Cancer 109: 653-660, 2004.
15. Kang Y, He W, Tulley S, et al: Breast cancer bone metastasis mediated by the Smad tumor suppressor pathway. PNAS 102: 13909-13914, 2005.

16. Javelaud D, Mohammad KS, McKenna CR, et al: Stable overexpression of Smad7 in human melanoma cells impairs bone metastasis. Cancer Res 67: 2317-2324, 2007.

17. Shah K and Weissleder R: Molecular optical imaging: applications leading to the development of present day therapeutics. NeuroRx 2: 215-225, 2005.

18. Li C, Wang W, Wu Q, et al: Dual optical and nuclear imaging in human melanoma xenografts using a single targeted imaging probe. Nucl Med Biol 33: 349-358, 2006.

19. Steinbrink J, Liebert A, Wabnitz H, et al: Towards noninvasive molecular fluorescence imaging of the human brain. Neurodegener Dis 5: 296-303, 2008. 